\title{
The Effectiveness of Positive Thinking Training on Perceived Stress, Metacognitive Beliefs and Death Anxiety in Women with Breast Cancer
}

\author{
Mojtaba Moin Vaziri ${ }^{1}$, Parvin Ehteshamzadeh ${ }^{2}$, Farah Naderi ${ }^{3}$, Sahar Safarzadeh $^{4}$ \\ 1. Department of Health Psychology, Khorramshahr-Persian Gulf International Branch, Islamic Azad University, Khorramshahr, \\ Iran \\ 2. Associate Professor, Department of Psychology, Ahvaz Branch, Islamic Azad University, Ahvaz, Iran \\ 3. Professor, Department of Psychology, Ahvaz Branch, Islamic Azad University, Ahvaz, Iran \\ 4. Assistant Professor, Department of Psychology, Ahvaz Branch, Islamic Azad University, Ahvaz, Iran \\ * Corresponding author's Email: p_ehtesha85@yahoo.com
}

\begin{abstract}
The aim of this study was to evaluate the effectiveness of positive thinking training on perceived stress, metacognitive beliefs, and death anxiety in women with breast cancer. The research method was experimental (pre-test-post-test design with an equal control group). The sample consisted of 30 women with breast cancer who were selected by convenience sampling. Then, from the sample, 15 women with breast cancer were randomly assigned to the experimental group and 15 women with breast cancer to the control group. The research instruments included Cohen et al.'s (1983) Perceived Stress Questionnaire, the Wells Metacognitive Beliefs Questionnaire (2004), and the Templer Death Anxiety Questionnaire (1970). Multivariate and univariate covariance methods were used to analyze the data. The results of data analysis showed that positive thinking training reduced perceived stress, metacognitive beliefs, and death anxiety in women with breast cancer in the experimental group compared to the control group ( $\mathrm{p}<.001)$. As a result, it can be said that positive thinking training with positive thinking techniques is effective in reducing perceived stress, metacognitive beliefs, and death anxiety in women with breast cancer.

Keywords: Positive Thinking Training, Perceived Stress, Metacognitive Beliefs, Death Anxiety
\end{abstract}

\section{Introduction}

Breast cancer is one of the main causes of death of women in the world, and it is the second major cause of cancer death. In the world, breast cancer accounts for almost $21 \%$ of all cancers (Momenimovahed \& Salehiniya, 2019). Breast cancer is a stiff mass that starts in the mammary ducts and invades the anterior tissue. The appearance of a large mass in the axillary lymph nodes is a sign of host failure. It can be said that despite these problems, considering that the breast is an important part of a woman's body image, any abnormality in this area can lead to cognitive problems for these women (Przezdziecki

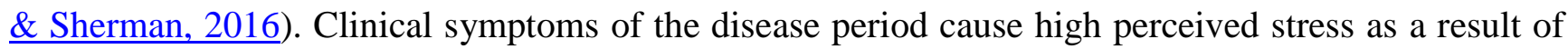
which, individual-social relations and individual-social adjustment are disrupted. These women are replete with feelings of boredom, sadness, hopelessness, discouragement, loneliness and dissatisfaction. The adverse effects of high perceived stress on these individuals affect the mental state during the disease (Colby \& Shifren, 2013). It should be said that perceived stress is a dominant problem in these people. Research has shown that stress involves physical, mental, and emotional reactions that are experienced as a result of changes in a person's life needs. These changes, large or small, disrupt patients. Perceived stress impairs a person's perceived ability and confidence in the face of stress, and leads to 
mood problems ( $\mathrm{Su}$ et al., 2017). On the other hand, patients with breast cancer suffer from metacognitive beliefs that threaten their mental health due to the pain of the disease challenge. Metacognitive beliefs cause disorders that affect a person's thinking style and adaptation (Hoffart, Johnson, Nordahl, \& Wells, 2018). Metacognitive beliefs make people anxious and worried. Patients often resort to metacognitive beliefs to relieve anxiety. Metacognitive beliefs, unwanted or disturbing thoughts are a major problem for people with special diseases because the feeling of threat and negative emotions have become permanent in them. From the point of view of psychologists, this type of coping style is inefficient and inconsistent coping because it does not help to solve problems and worsens a person's psycho-mood (Hoffart et al., 2018). On the other hand, it should be said that due to stressrelated distress, fear of cancer, the anxiety rate of death of these people is high. Death anxiety is one of the factors that disturb the mental balance of patients. In these patients, due to the specific condition of the disease, the resulting deaths induce death anxiety more than other diseases (Bibi \& Khalid, 2020). Death anxiety is closely related to the underlying fear associated with the destruction of a person's being. Death anxiety includes overt or covert horror elements that vary in magnitude, and are differentiated from actual experience. Perception of threat affects the degree of death anxiety. Important cognitive elements of death anxiety include attitude, ability to imagine prediction, expectation of the future, and awareness of the obviousness of death (Tomer \& Eliason, 1996). Positive thinking training can be an effective way to control perceived stress, metacognitive beliefs, and death anxiety in women with breast cancer. According to research findings, positive thinking training reduces stress by influencing cognitive problems (Taghizadeh \& Aflakifard, 2017). Basharpoor, Kazemi, and Salehi (2019) showed that positive thinking training has a significant effect on reducing self-determination and death anxiety in women with breast cancer. Casellas-Grau, Font, and Vives (2014) determined that positive thinking training is effective in reducing the perception of stress and anxiety in women with breast cancer. Dowlatabadi et al. (2016) found that positivity training has a significant effect on depression and happiness in breast in women with breast cancer. Jamshidifar et al. (2015)showed in a study that receiving positive thinking training intervention is effective on the psychological well-being of breast cancer patients. Saeedi, Sharbaf, Ebrahimabad, and Kareshki (2019) found that positive thinking training has a significant effect on reducing death anxiety in women with breast cancer. Jassim, Whitford, Hickey, and Carter (2015) showed that reducing death anxiety in women with breast cancer through positive thinking training is an effective method. McGregor and Antoni (2009); (Mohabbat-Bahar, Maleki-Rizi, Akbari, \& Moradi-Joo, 2015) found that positive thinking training has an effect on reducing stress in women with breast cancer. It should be said that positive psychology is the scientific study of virtues and human strengths. Positive thinking training plays a role in the well-being of individuals. Positive Thinking Training uses theories, researches, and techniques of psychological intervention to identify the components of satisfactory, adaptive, creative, and emotional human behavior, and the scientific study of human experiences is the positive attributes of individuals and institutions that make a difference in people (Jassim et al., 2015). Women with breast cancer have high levels of stress due to their emotional, cognitive, mood, and physical problems and physical problems 
caused by the disease. In these women, such problems increase the level of metacognitive beliefs, death anxiety, and rumination, so, these problems can disrupt the treatment process. Due to the special situation of breast cancer patients, there is a concern about using a treatment which has a significant effect on reducing stress and rumination of these patients, which disrupt the quality of life of them by increasing death anxiety among them. Life and cognitive improvement of patients requires taking the best educational approach. Positive Thinking Training helps people recognize their positive experience in dealing with difficult situations, boost their self-esteem, well-being, resilience to stress, stress, rumination, and anxiety. It also makes them calm and establishes hope in them. It should be said that due to the severity of the symptoms of this disease and the high degree of disability of researchers, therapists have always sought to find the best effective ways to reduce physical and psychological problems of women with breast cancer on the one hand, and increase their ability on the other hand. It is very important to recognize what treatment is effective in a short period of time. In recent years, the role of psychological factors in the occurrence of the disease has become significant. It should be noted that an effective protocol can be identified to reduce perceived stress, metacognitive beliefs, and death anxiety in women with breast cancer. Evaluation of therapeutic intervention, factors modulating the stress and the rate of metacognitive beliefs of these women reduces their death anxiety, and can be effective in improving the quality of life of these patients in therapeutic centers. The aim of this study was to investigate the effectiveness of positive thinking training on perceived stress, metacognitive beliefs, and death anxiety in women with breast cancer. In other words, this study seeks to see whether positive thinking training has an effect on perceived stress, metacognitive beliefs, and death anxiety in women with breast cancer.

\section{Material and Methods}

In this study, an experimental research method (pre-test-post-test design with an equal control group) was used. This research method was used because the current study sought to investigate the effectiveness of positive thinking training on perceived stress, metacognitive beliefs, and death anxiety in women with breast cancer. Before performing the positive thinking training intervention, women with breast cancer selected in each group were measured in terms of their perceived stress test, metacognitive beliefs, and death anxiety. The role of pretest in this project was to control and compare perceived stress, metacognitive beliefs, and death anxiety of experimental and control groups in pre-test and post-test. Then, after the positive thinking training sessions, metacognitive beliefs and death anxiety questionnaires were administered in three experimental groups and the control group after the perceived stress test. As a result, it was possible to determine whether the changes in perceived stress, metacognitive beliefs, and death anxiety in women with breast cancer were due to positive thinking training sessions.

\section{Statistical Population}


The statistical population in the present study included all women with breast cancer who referred to Omid Center in Bandar Abbas in 2019.

\section{Statistical sample and sampling method}

In this study, the sample size, based on previous research and according to Cochran's formula, included 30 women with breast cancer with an error value of .05, who were selected by available sampling. Thus, first, a list of women with breast cancer was prepared, according to the list and based on inclusion criteria (by exclusion of mastectomy and chemotherapy) including living in Bandar Abbas during treatment sessions, ability to attend treatment sessions, lack of consumption of psychiatric drugs three months before and during the research, a minimum level of writing literacy, suffering from the breast cancer for 6 months as the minimum duration of illness, no severe neuropsychiatric disorders such as major hypertension, epilepsy, vision problems, and severe hearing. Moreover, the exclusion criteria included psychotic disorders, cognitive-personality disorders, initiation of other psychotherapy processes simultaneously, and absence in more than two treatment sessions in the treatment process. Finally, 33 women with breast cancer were included and according to Cochran's formula, 30 patients were selected through available sampling. Then, from the study sample, 15 women with breast cancer were randomly assigned to the experimental group, and 15 women with breast cancer to the control group.

\section{Research tools}

Perceived Stress Questionnaire: This questionnaire was developed by Cohen, Kamarck, and Mermelstein (1983). This scale was designed to help respondents express their views on the uncontrollability, unpredictability, and hardship of their lives. This questionnaire consists of 14 questions in Likert format in a range from 1 (none) to 5 (very high). In this questionnaire, questions 4 5-6-6-7-9-10-13 are scored in reverse. The minimum and maximum perceived stress questionnaires are equal to 14,70 . The validity of the questionnaire was measured through factor analysis in the study by Pasha and Bozorgian (2011) as $66.01 \%$, which showed the high validity of the questionnaire. In addition, they were reported the reliability of the questionnaire by Cronbach's alpha and Bisection methods as $0.87,0.88$. In the present study, the reliability of the questionnaire was 0.78 by Cronbach's alpha method. Metacognitive Beliefs Questionnaire: This questionnaire, developed by Wells and Cartwright-Hatton (2004), is a 30-item self-report tool that measures people's beliefs about their thinking. This tool was designed to measure several metacognitive elements and characteristics, some of which play a pivotal role in the metacognitive model of psychological disorder. This scale has five subscales: 1) Positive beliefs about worry, 2) Beliefs about uncontrollability, thought risk, 3) Beliefs about cognitive confidence, 4) Beliefs about the need to control thoughts, and 5) Cognitive self-awareness. In Wells and Cartwright-Hatton (2004) study, the range of Cronbach's alpha coefficient for subscales ranged from .72 to .93 , and its test-retest reliability after a period of 18 to 22 days was .75 . In addition, the reliability coefficients of the subscales were reported from .59 to .87 . In the present study, the reliability of the questionnaire with Cronbach's alpha method was obtained $.82, .85, .87, .84$, and .83 for positive beliefs 
about anxiety, uncontrollability-risk, cognitive confidence, need to control thoughts, and cognitive selfawareness, respectively.

Templer Death Anxiety Questionnaire: This questionnaire, developed by Templer et al. (2006), is an effective tool for measuring anxiety and fear of death. This scale consists of 14 yes/no questions with no time limit and is scored in a range from zero to fourteen. A person's high score indicates a high level of anxiety and fear of death. Nia et al. (2014) reported the Cronbach's reliability coefficients of the questionnaire as 0.87 and 0.89 , which showed the high reliability of the questionnaire. In the present study, the Cronbach's reliability of the questionnaire was obtained .74.

Positive Thinking Skills Training Sessions: Positive Thinking Training Sessions, based on the Power of Positive Thinking Norman (2010), translated by Hosseini (2018) were conducted in 8 90-minute sessions in the experimental group (Pourrazavi \& Hafezian, 2017). The summary of the sessions is as follows:

Table 1. Summary of Positive Thinking Skills Training Sessions

\begin{tabular}{|c|c|}
\hline sessions & Description \\
\hline First session & $\begin{array}{l}\text { Introduction session. Administering pre-test. Introducing and arranging for the training process based on the } \\
\text { positivist approach. } \\
\text { Explaining the effect of positivist thinking on the development of emotional dimensions. } \\
\text { Explaining the meaning and concept of positive thinking. }\end{array}$ \\
\hline second session & $\begin{array}{l}\text { Positive modeling of coping with stress } \\
\text { Flexibility: adaptation change, stability in turmoil, authoritative leadership } \\
\text { Link: Support, respect, compromising damaged relationships, and forgiving } \\
\text { Self-awareness and self-scrutiny training }\end{array}$ \\
\hline third session & $\begin{array}{l}\text { Teaching positivity processes } \\
\text { Sharing excitement: talking about pleasure, pain, mutual empathy, responsibility, enjoyable interactions, and } \\
\text { humor } \\
\text { Collaborative problem solving: problem identification, brainstorming, joint decision making, focusing on goals, } \\
\text { building on success } \\
\text { Teaching admission } \\
\text { Increased defects in the disease situation. }\end{array}$ \\
\hline fourth Session & $\begin{array}{l}\text { Guidelines for strengthening a positive attitude in the treatment process } \\
\text { Explaining meaning of difficulty: normalization, sense of coherence and explanatory documents } \\
\text { Positive Outlook: Hope, Courage and Encouragement, Seize Opportunities, Accept What Cannot Be Changed } \\
\text { Expressive expression of emotions } \\
\text { Identifying responsibilities } \\
\text { Being responsible }\end{array}$ \\
\hline Fifth Session & $\begin{array}{l}\text { Positive hope } \\
\text { Training to have hope in the challenge process } \\
\text { Assessing the amount of stress and potential forces on the individual, and thinking positively about their abilities } \\
\text { Strengthening positive thinking } \\
\text { Optimism and hope training } \\
\text { Training on negative-irrational thoughts }\end{array}$ \\
\hline Sixth Session & $\begin{array}{l}\text { Positive reinforcement of thought in women by controlling stress } \\
\text { Facilitating compatibility } \\
\text { Effective family processes on stress management } \\
\text { Learning to share excitement and get support } \\
\text { Teach positivity, identify your positive traits }\end{array}$ \\
\hline Seventh session & $\begin{array}{l}\text { Forming resilience to challenge with positivity } \\
\text { Keeping spirit } \\
\text { Teaching positive self-talk about self and its impact on behavior and cognitive dimensions }\end{array}$ \\
\hline
\end{tabular}




\begin{tabular}{|l|l|}
\hline Eighth session & $\begin{array}{l}\text { Summary of Positive Thinking Skills Training } \\
\text { Teaching the connection between positive thoughts and emotions and behavior } \\
\text { Summary of meetings } \\
\text { Submitting suggestions and administering post-test }\end{array}$ \\
\hline
\end{tabular}

\section{Results}

Mean and standard deviation of perceived stress, metacognitive beliefs, and death anxiety in experimental and control groups in pre-test and post-test are presented in table 2.

Table 2. Descriptive statistics of research variables in experimental group $(n=15)$ and control group $(n=15)$

\begin{tabular}{|c|c|c|c|c|}
\hline Variable & Group & Phase & Mean & SD \\
\hline \multirow[t]{4}{*}{ Perceived Stress } & \multirow[t]{2}{*}{ experimental } & pre-test & 63.60 & 4.08 \\
\hline & & post-test & 17.01 & 2.32 \\
\hline & \multirow[t]{2}{*}{ control } & pre-test & 52.60 & 4.54 \\
\hline & & post-test & 54.10 & 4.37 \\
\hline \multirow[t]{4}{*}{ Positive belief about worry } & \multirow[t]{2}{*}{ experimental } & pre-test & 21.26 & 2.18 \\
\hline & & post-test & 8.40 & 1.54 \\
\hline & \multirow[t]{2}{*}{ control } & pre-test & 20.73 & 1.48 \\
\hline & & post-test & 20.53 & 1.76 \\
\hline \multirow[t]{4}{*}{ Belief in uncontrollability - thoughts risk } & \multirow[t]{2}{*}{ experimental } & pre-test & 22.40 & 1.18 \\
\hline & & post-test & 8.60 & .98 \\
\hline & \multirow[t]{2}{*}{ control } & pre-test & 21.20 & 2.07 \\
\hline & & post-test & 21.86 & 1.35 \\
\hline \multirow[t]{4}{*}{ Cognitive confidence } & \multirow[t]{2}{*}{ experimental } & pre-test & 23.13 & 1.06 \\
\hline & & post-test & 7.93 & 1.09 \\
\hline & \multirow[t]{2}{*}{ control } & pre-test & 20.32 & 1.87 \\
\hline & & post-test & 21.26 & 1.16 \\
\hline \multirow[t]{4}{*}{ Belief in the need to control thoughts } & \multirow[t]{2}{*}{ experimental } & pre-test & 22.33 & 1.49 \\
\hline & & post-test & 6.66 & 1.39 \\
\hline & \multirow[t]{2}{*}{ control } & pre-test & 21.20 & 2.04 \\
\hline & & post-test & 21.26 & 2.12 \\
\hline \multirow[t]{4}{*}{ Cognitive self-awareness belief } & \multirow[t]{2}{*}{ experimental } & pre-test & 23.13 & .91 \\
\hline & & post-test & 6.93 & 1.75 \\
\hline & \multirow[t]{2}{*}{ control } & pre-test & 22.01 & 1.46 \\
\hline & & post-test & 21.66 & 1.87 \\
\hline \multirow[t]{4}{*}{ death anxiety } & \multirow[t]{2}{*}{ experimental } & pre-test & 12.86 & .91 \\
\hline & & post-test & 3.01 & 1.30 \\
\hline & \multirow[t]{2}{*}{ control } & pre-test & 12.46 & 1.37 \\
\hline & & post-test & 12.33 & 1.45 \\
\hline
\end{tabular}


As shown in Table 3, the null hypothesis for the normal distribution of scores in the experimental group and the control group on the variables of perceived stress, metacognitive beliefs, and death anxiety was confirmed. That is, the assumption of normal distribution of scores in the pretest was confirmed in both experimental and control groups. Furthermore, the assumptions of regression homogeneity and homogeneity of variances were confirmed.

Table 3. Results of Kolmogorov-Smirnov test on the default of normal distribution of scores

\begin{tabular}{|c|c|c|c|}
\hline \multirow{2}{*}{ Variables } & \multirow{2}{*}{ Groups } & Kolmogorov-Smirnov \\
\cline { 2 - 4 } & & Statistics & Significance \\
\hline Perceived Stress & \multirow{2}{*}{ Experiment } & .20 & .8 \\
\cline { 2 - 4 } & Control & .15 & .09 \\
\hline Positive belief about worry & Experiment & .08 & .20 \\
\cline { 2 - 4 } & Control & .10 & .20 \\
\hline Belief in uncontrollability-danger & Experiment & .09 & .20 \\
\cline { 2 - 4 } & Control & .11 & .20 \\
\hline Cognitive belief & Experiment & .10 & .20 \\
\cline { 2 - 4 } & Control & .17 & .16 \\
\hline \multirow{2}{*}{ Belief requires control of thoughts } & Experiment & .11 & .20 \\
\cline { 2 - 4 } & Control & .17 & .16 \\
\hline \multirow{2}{*}{ Cognitive self-awareness belief } & Experiment & .11 & .19 \\
\cline { 2 - 4 } & Control & .08 & .20 \\
\hline
\end{tabular}

According to results, there was a significant difference between the experimental and control groups regarding one of the dependent variables $(\mathrm{F}=124.69$ and $\mathrm{p}<0.001)$. According the table 5 , there was a significant difference between the experimental and control groups in terms of perceived stress $(\mathrm{F}=$ 241.24, $\mathrm{p}<.001)$, belief Positive about anxiety $(\mathrm{F}=135.43, \mathrm{p}<.001)$, uncontrollable-risk belief $(\mathrm{F}=$ $149.18, \mathrm{p}<.001)$, cognitive belief $(\mathrm{F}=3115.15, \mathrm{p}<.001) \mathrm{p})$, belief in the need to control thoughts $(\mathrm{F}=$ 163.83, $\mathrm{p}<.001)$, cognitive self-awareness belief $(\mathrm{F}=127.07, \mathrm{p}<.001)$ and death anxiety $(\mathrm{F}=98.78, \mathrm{p}$ $<.001)$.

\section{Discussion}

The aim of this study was to evaluate the effectiveness of positive thinking training on perceived stress, metacognitive beliefs, and death anxiety in women with breast cancer. The results showed that there was a significant difference between women with breast cancer in the experimental and control groups in terms of perceived stress, positive belief about anxiety, uncontrollable-risk belief, cognitive belief, belief in the need to control thoughts, cognitive self-awareness belief, and death anxiety. In other words, 
positive thinking training significantly reduced perceived stress, metacognitive beliefs, and death anxiety in women with breast cancer in the experimental group compared to the mean of the control group. This finding is consistent with the result obtained in previous studies (Basharpoor et al., 2019; Casellas-Grau et al., 2014; Mohabbat-Bahar et al., 2015; Taghizadeh \& Aflakifard, 2017).

In explaining the results, it can be said that women with breast cancer do not have suitable conditions due to the perception of stress and anxiety of death from their specific disease, and these people always have high worries which aggravate their problems in the treatment process. In this study, it was found that positive thinking training reduces perceived stress and death anxiety in women with breast cancer. Positive thinking training intervention provided women with breast cancer with useful solutions, helped them identify negative thoughts about the inability to control stress and anxiety, made them identify their own perceived stresses, and increased their ability to cope, stubbornness as well as their internal resistance to stress. In women with breast cancer, the training reinforced positive thinking about hope, positive thinking about their abilities, and optimism. The training helped women with treatment to identify negative and irrational thoughts by addressing stress, tension, and anxiety. Death and anxiety caused by the problems of the disease were reduced in them and caused them to recognize the symptoms of stress and anxiety of death in themselves. Moreover, through dominating the role of optimism, hope in adjusting the problems and stressors in the situation wherein they are, the level of internal resistance increases in confronting stress and stressful conditions. Furthermore, the stubborn structure of patients, including stress management, coping with these conditions, their struggle, positive thinking and their purposefulness in combating cancer stress is enhanced, and isolation and helplessness are reduced.

In the face of stress and anxiety, death was reduced, and they could recognize their positive experience in dealing with difficult and stressful conditions caused by illness and strengthen their self-esteem and self-esteem, and cause. This in turned contributed to higher level of well-being, resistance to stress and anxiety, quiet and hopefulness in them. It should be said that positive thinking training strengthened positive thinking in women, facilitated adjustment, emotion regulation, as well as positivity and identification of its positive features, and the growth of this feature in women with breast cancer. They controlled the negative effects and reduced their death anxiety, and by reducing stress and anxiety, they experienced more peace of mind due to positive thinking.

It can be said that training positive thinking in women with breast cancer enabled them to have a good understanding of behaviors, attitudes, and feelings and reduce stress by keeping calmness and composure. As a result of indoctrination, repetition and practice, the minds of women with breast cancer became positive, and this positivity continued to create a good mood and control the anxiety of their death.

In the present study, it was found that positive thinking training is effective in reducing the metacognitive beliefs of women with breast cancer. The ability to have positive thoughts in women with breast cancer is reduced under the effect of the type of disease and their attitude and rumination of thoughts in the treatment cycle. However, training positive thinking contributed to strengthening and improving positive relationships with others, their happiness and success. Positive thinking training encouraged 
them to recognize their positive and good experiences and their role in increasing and enhancing their self-esteem, and have a happy and joyful spirit. This led to moderation of negative consequences of rumination on the disease. Negative metacognitive beliefs that caused great concern in these women were controlled, and the level of metacognitive beliefs decreased in them due to the creation of positive waves in their thoughts.

Having a positive mindset led women to take an active position, and shape their lives personally, and this positive thinking and avoidance of negative thoughts became a good strategy to moderate the stress caused by rumination. Positive thinking training helped them to reduce psychological problems, stress and anxiety, create psychological comfort (mental well-being), hope and optimism for the future, and develop interpersonal skills, aesthetic feelings, perseverance, and endurance. It can be said that the training of positive thinking skills in women with breast cancer who are in an important stage of treatment led to the identification of flexibility in the face of their problems, and this made them stubbornly construct and repair themselves. Thinking caused these women to show fewer negative thoughts and metacognitive beliefs due to their physical condition, because training caused positive thinking and hope in them. It can be stated that the teaching of positive thinking by creating a system of optimism in women, has led to the establishment of hope in them, and this, in long run, contributed to reducing metacognitive beliefs. As a result, it can be stated that positive thinking training is effective in reducing perceived stress, metacognitive beliefs and death anxiety in women with breast cancer.

\section{Limitations}

- Due to the condition of women with breast cancer, random selection was not possible and the researcher selected non-random individuals that may have affected the results.

- The control of social, economic, and family conditions of women with breast cancer was beyond the control of the researcher.

\section{Suggestions}

- In future research, it is suggested that researchers examine the effectiveness of positive thinking training on perceived stress, metacognitive beliefs, and death anxiety in other cancer patients so that the results can be generalized with more confidence.

- It is suggested that counseling and treatment centers pay attention to the effectiveness of positive thinking training on reducing perceived stress, metacognitive beliefs, and death anxiety in women with breast cancer, and use positive thinking training due to its effectiveness.

- In the workshops, the therapist should be taught the method of positive thinking through therapeutic authorities so that this intervention can be used to improve the perceived stress, metacognitive beliefs, and death anxiety of women with breast cancer.

- It is suggested that health care providers pay special attention to the effect of positive thinking training on patient referral policies by identifying the effectiveness of this training in medical centers and prepare medical centers so that they can make optimal use of this effective protocol to alleviate the cognitive problems of women with breast cancer. 
Conflict of interest: The authors state no conflict of interest in the study.

Financial sponsor: The authors acknowledge that they have not received any financial support for all stages of the study, writing and publication of the paper.

Acknowledgment: We hereby appreciate all the participants of the study as well as all those participating in the implementation of this project.

\section{References}

Basharpoor, S., Kazemi, N., \& Salehi, M. (2019). The Effectiveness of Positive Group Psychotherapy on Self-Determination and Death Anxiety in Women with Breast Cancer. JOURNAL OF SABZEVAR UNIVERSITY OF MEDICAL SCIENCES, 25(5), 731-739

Bibi, A., \& Khalid, M. A. (2020). Death anxiety, perceived social support, and demographic correlates of patients with breast cancer in Pakistan. Death studies, 44(12), 787-792.

Casellas-Grau, A., Font, A., \& Vives, J. (2014). Positive psychology interventions in breast cancer. A systematic review. Psycho-Oncology, 23(1), 9-19.

Cohen, S., Kamarck, T., \& Mermelstein, R. (1983). A global measure of perceived stress. Journal of health and social behavior, 24, 385-396.

Colby, D. A., \& Shifren, K. (2013). Optimism, mental health, and quality of life: a study among breast cancer patients. Psychology, health \& medicine, 18(1), 10-20.

Dowlatabadi, M. M., Ahmadi, S. M., Sorbi, M. H., Beiki, O., Razavi, T. K., \& Bidaki, R. (2016). The effectiveness of group positive psychotherapy on depression and happiness in breast cancer patients: A randomized controlled trial. Electronic physician, 8(3), 2175.

Hoffart, A., Johnson, S. U., Nordahl, H. M., \& Wells, A. (2018). Mechanisms of change in metacognitive and cognitive behavioral therapy for treatment-resistant anxiety: The role of metacognitive beliefs and coping strategies. Journal of Experimental Psychopathology, 9(3), 1-10.

Jamshidifar, Z., Shemirani, S. M., Ahramian, A., Ahmadi, A., Lory, S. S., \& Moradi-Joo, M. (2015). The effectiveness of positive psychotherapy on the psychological well-being of breast cancer patients. Ciência e Natura, 37, 432-436.

Jassim, G. A., Whitford, D. L., Hickey, A., \& Carter, B. (2015). Psychological interventions for women with non-metastatic breast cancer. Cochrane Database of Systematic Reviews(5), 1-79.

McGregor, B. A., \& Antoni, M. H. (2009). Psychological intervention and health outcomes among women treated for breast cancer: a review of stress pathways and biological mediators. Brain, behavior, and immunity, 23(2), 159-166. 
Mohabbat-Bahar, S., Maleki-Rizi, F., Akbari, M. E., \& Moradi-Joo, M. (2015). Effectiveness of group training based on acceptance and commitment therapy on anxiety and depression of women with breast cancer. Iranian journal of cancer prevention, 8(2), 71-76.

Momenimovahed, Z., \& Salehiniya, H. (2019). Epidemiological characteristics of and risk factors for breast cancer in the world. Breast Cancer: Targets and Therapy, 11, 151-164.

Nia, H. S., Ebadi, A., Lehto, R. H., Mousavi, B., Peyrovi, H., \& Chan, Y. H. (2014). Reliability and validity of the persian version of templer death anxiety scale-extended in veterans of Iran-Iraq warfare. Iranian journal of psychiatry and behavioral sciences, 8(4), 29-37.

Pasha, G., \& Bozorgian, R. (2011). The Relationship Between Metacognition, Perfectionism And SelfEfficacy, With Perceived Stress In The Students Of Azad Ahvaz University. JOURNAL OF SOCIAL PSYCHOLOGY (NEW FINDINGS IN PSYCHOLOGY), 6(18), 91-102.

Pourrazavi, S. S., \& Hafezian, M. (2017). The Effectiveness Of Teaching Positive Thinking Skills On Social, Emotional, And Academic Adjustment Of High School Students. Journal of school psychology, 6(1), 26-48.

Przezdziecki, A., \& Sherman, K. A. (2016). Modifying affective and cognitive responses regarding body image difficulties in breast cancer survivors using a self-compassion-based writing intervention. Mindfulness, 7(5), 1142-1155.

Saeedi, N. R., Sharbaf, H. A., Ebrahimabad, M. J. A., \& Kareshki, H. (2019). Psychological consequences of breast cancer in Iran: a meta-analysis. Iranian journal of public health, 48(5), 816824.

Su, J.-A., Yeh, D.-C., Chang, C.-C., Lin, T.-C., Lai, C.-H., Hu, P.-Y., . . Gossop, M. (2017). Depression and family support in breast cancer patients. Neuropsychiatric disease and treatment, 13, 2389.

Taghizadeh, L., \& Aflakifard, H. (2017). The effectiveness of positive thinking training on stress and self-efficacy of elementary school's girl students of Jahrom in 2015-2016. Indian Journal of Positive Psychology, 8(3), 379-381.

Templer, D. I., Awadalla, A., Al-Fayez, G., Frazee, J., Bassman, L., Connelly, H. J., . . Abdel-Khalek, A. M. (2006). Construction of a death anxiety scale-extended. OMEGA-Journal of Death and Dying, 53(3), 209-226.

Tomer, A., \& Eliason, G. (1996). Toward a comprehensive model of death anxiety. Death studies, 20(4), 343-365.

Wells, A., \& Cartwright-Hatton, S. (2004). A short form of the metacognitions questionnaire: properties of the MCQ-30. Behaviour research and therapy, 42(4), 385-396. 